Article

\title{
Development of an Immunochromatographic Strip Test for the Rapid Detection of Alternariol Monomethyl Ether in Fruit
}

\author{
Yan Man ${ }^{1,2,3}$, Gang Liang 1,2,3, Fuchao Jia ${ }^{4}$, An Li ${ }^{1,2,3}$, Hailong Fu ${ }^{1,2,3}$, Meng Wang ${ }^{1,2,3}$ \\ and Ligang Pan 1,2,3,* \\ 1 Beijing Research Center for Agricultural Standards and Testing, Beijing Academy of Agriculture and \\ Forestry Sciences, Beijing 100097, China; manyan3669@163.com (Y.M.); liangg@brcast.org.cn (G.L.); \\ lia@brcast.org.cn (A.L.); fuhl@brcast.org.cn (H.F.); wangm@brcast.org.cn (M.W.) \\ 2 Risk Assessment Lab for Agro-Products (Beijing), Ministry of Agriculture P.R. China, Beijing 100125, China \\ 3 Beijing Municipal Key Laboratory of Agriculture Environment Monitoring, Beijing 100097, China \\ 4 School of Science, Shandong University of Technology, Zibo 255000, Shandong, China; \\ jiafuchao@sdut.edu.cn \\ * $\quad$ Correspondence: panlg@brcast.org.cn; Tel.: +86-10-5150-3013; Fax: +86-10-5150-3793
}

Academic Editor: Laura Anfossi

Received: 30 March 2017; Accepted: 22 April 2017; Published: 29 April 2017

\begin{abstract}
A rapid, portable, and semi-quantitative immunochromatographic strip was developed for rapid and visual detection of alternariol monomethyl ether (AME). For this purpose, the anti-AME monoclonal antibody $(\mathrm{mAb})$ was prepared and identified. AME coupled to bovine serum albumin (BSA) via methyl 4-bromobutanoate was prepared as immunogen. The recoveries of AME in spiked cherry and orange fruits determined by competitive ELISA were $86.1 \%$ and $80.7 \%$, respectively. A colloidal gold nanoparticle (CGN) and CGNs-mAb conjugate were synthesized, and on this basis, a competitive colloidal gold immunochromatographic strip was developed and applied to the detection of AME toxin in fruit samples. The intensity of red density of the test line (T line) is inversely proportional to AME concentration in the range $0.1-10 \mathrm{ng} / \mathrm{mL}$. The visual limit of detection (LOD) of AME was found to be about $10 \mathrm{ng} / \mathrm{mL}$. The semi-quantitative detection can be completed in $10 \mathrm{~min}$. Moreover, the immunochromatographic strip has lower cross-reactivity with AME analogues, and it has a good stability performance (following 3 months of storage). Hence, the colloidal gold immunochromatographic strip could be used as a semi-quantitative tool for the on-site, rapid, and visual detection of AME in fruit.
\end{abstract}

Keywords: alternariol monomethyl ether (AME); monoclonal antibody; immunochromatographic strip test; colloidal gold nanoparticle; competitive ELISA

\section{Introduction}

Alternariol monomethyl ether (AME, 3, 7-Dihydroxy-9-methoxy-1-methyl-6H-dibenzo [b, d] pyran-6-one) is one of the major Alternaria mycotoxins. AME is structurally related to alternariol $(\mathrm{AOH})$ and altenuene (ALT), and belongs to dibenzo- $\alpha$-pyrone derivatives which are produced by Alternaria alternata, Alternaria solani and some other species within the genus Alternaria [1,2]. AME is distributed all over the world and shows no acute toxic effects to the health of humans and animals [3], but it possesses the properties of mutagenicity and carcinogenicity, causing particularly high incidences of esophageal cancer [4]. It also can induce DNA breaks [5]. Moreover, AME was characterized as a powerful inhibitor for topoisomerase I and topoisomerase II, contributing to its genotoxicity [6,7]. As a result, it is important and urgent to develop sensitive and specific analytical methods for qualitative and quantitative detection of AME. 
At present, the main analytical methods for detecting AME in foods and agricultural products are gas chromatography (GC) and liquid chromatography-mass spectrometry (LC-MS). GC is suitable for detecting non-polar and volatile compounds, however, AME toxin is made up of small, polar, and non-volatile molecules [8], hence, its analysis usually needs derivatization prior to GC analysis [9]. The derivatization results in potential disadvantages for GC analysis such as matrix interference, the time-consuming nature of the process, the need for an expensive derivatization reagent, and so on. In the last few years, LC-MS, especially LC tandem mass spectrometry (LC-MS/MS), has played an important role in AME detection without derivatization [10-12]. However, these methods need highly qualified technicians and can only be carried out in the lab.

The colloidal gold immunochromatographic strip test has been developed into a popular platform for application in food, feed, and agricultural products safety due to its potential for rapid, portable, on-site, and visual detection. Until now, it has been used for the detection of small molecular mycotoxins [13], such as ochratoxin A [14-16], deoxynivalenol [17,18], aflatoxin B1 [19], aflatoxin M1 [20], fumonisins B1, B2, and B3 [21], zearalenone [22], amatoxins [23], and T-2 Toxin [24,25]. In the current study, a highly specific monoclonal antibody (mAb) against AME was produced using AME- bovine serum albumin (BSA) as immunogen for the development of an anti-AME mAb-based colloidal gold immunochromatographic strip test method. This method was used to detect AME, an Alternaria mycotoxin, in fruit samples.

\section{Results}

\subsection{Carboxyl Derivative Modification of $A M E$}

The schematic of AME carboxyl derivative modification is shown in Figure 1. AME linked methyl ester (compound 1) and the AME linked carboxylic acid (compound 2) were revealed by NMR. The following ${ }^{1} \mathrm{H}-\mathrm{NMR}$ (400 MHz, DMSO) of AME linked methyl ester (compound 1) was produced: $\delta 11.81(\mathrm{~s}, 1 \mathrm{H}, 14), 7.28(\mathrm{~s}, 1 \mathrm{H}, 10), 6.91(\mathrm{~s}, 2 \mathrm{H}, 1$ and 3), $6.67(\mathrm{~s}, 1 \mathrm{H}, 12), 4.10$ (t, J = 6.1 Hz, $2 \mathrm{H}, 17), 3.93$ (s, $3 \mathrm{H}, 15), 3.63$ (s, $3 \mathrm{H}, 21), 2.79$ (s, $3 \mathrm{H}, 16), 2.49-2.42$ (m, $2 \mathrm{H}, 19), 2.07-1.93$ (m, $2 \mathrm{H}, 18)$. The following ${ }^{1} \mathrm{H}-\mathrm{NMR}(400 \mathrm{MHz}, \mathrm{DMSO})$ of AME linked carboxylic acid (compound 2) was produced: $\delta 12.17$ (s, $1 \mathrm{H}, 21), 11.79$ (s, $1 \mathrm{H}, 14), 7.19(\mathrm{~s}, 1 \mathrm{H}, 10), 6.85(\mathrm{~d}, J=7.0 \mathrm{~Hz}, 2 \mathrm{H}, 1$ and 3), $6.61(\mathrm{~d}, J=1.7 \mathrm{~Hz}$, $1 \mathrm{H}, 12), 4.07$ (t, J = 6.4 Hz, $2 \mathrm{H}, 17), 3.90$ (s, $3 \mathrm{H}, 15), 2.73$ (s, 3 H, 16), 2.41 (t, J = 7.3 Hz, 2 H, 19), 1.97 $(\mathrm{p}, J=6.7 \mathrm{~Hz}, 2 \mathrm{H}, 18)$. The results of NMR indicated that AME was modified with methyl ester and carboxylic acid successfully, respectively. In addition, the yield and purity were $76 \%$ and $>95 \%$ for compound 1, respectively, and were $28 \%$ and $>98 \%$ for compound 2 , respectively.

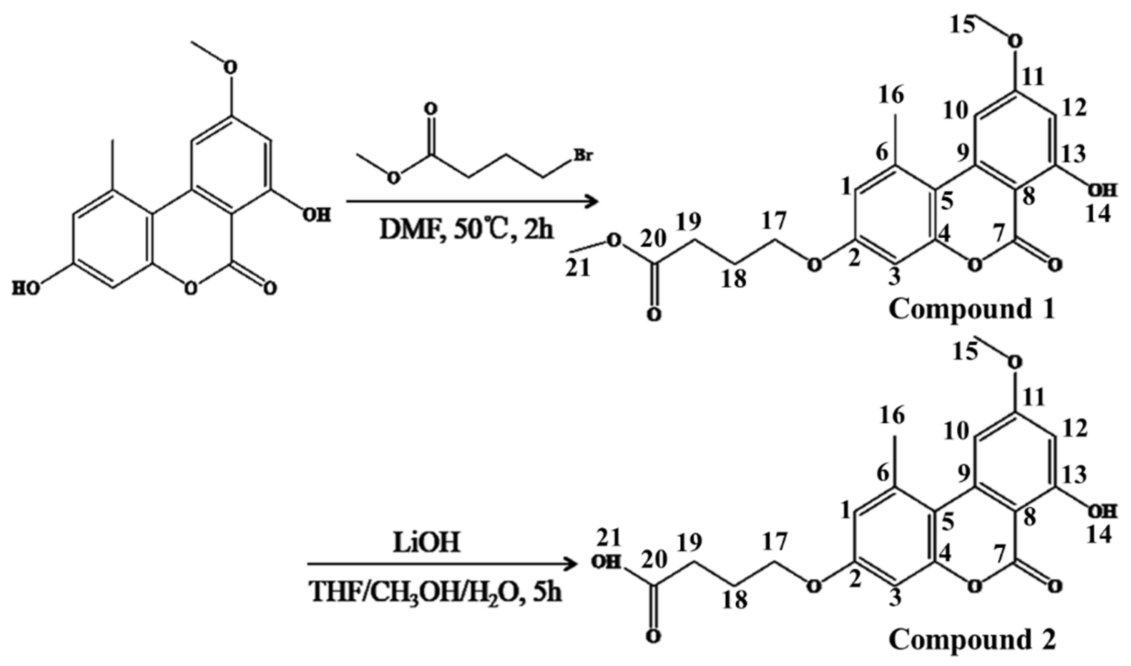

Figure 1. The schematic preparation of carboxyl derivative modification of alternariol monomethyl ether (AME). 


\subsection{Production and Characterization of Anti-AME $m A b$}

The specificity and sensitivity of immunoassay developed for detecting mycotoxin are dependent on the characteristics of mAb. Typical standard curves of competitive ELISA for AME are shown in Figure 2. According to Figure 2, the anti-AME mAb displayed a higher affinity for AME, the antibody titer $(>1: 90,000)$ was obtained, and the $50 \%$ inhibition concentration $\left(\mathrm{IC}_{50}\right)$ values of $\mathrm{AME}$ was $0.227 \mathrm{ng} / \mathrm{mL}$. In addition, due to the fact that the chemical structures of AOH and AME are very similar, the cross-reactivity of anti-AME mAb with AOH was also examined using competitive ELISA. The results showed that the anti-AME $\mathrm{mAb}$ was specific to AME, whereas the relative weak cross reactivity to $\mathrm{AOH}$ was determined to be $2.1 \%$.

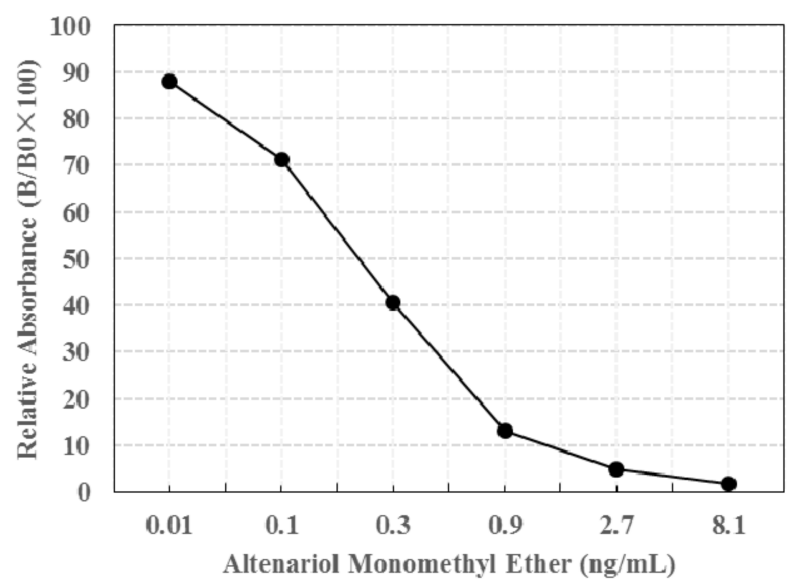

Figure 2. Typical standard curves of the competitive ELISA for alternariol monomethyl ether (AME). Three replicate wells of all the standard concentrations $(0.01,0.1,0.3,0.9,2.7,8.1 \mathrm{ng} / \mathrm{mL})$ were analyzed.

\subsection{Characterization of Colloidal Gold Nanoparticles (CGNs) and the CGNs-mAb Conjugates}

A transmission electron microscopy (TEM) image for the CGNs is shown in Figure 3a. The UV spectrum of CGNs and colloidal gold-AME mAb conjugate was detected by UV spectrophotometer at a wavelength of 400 to $600 \mathrm{~nm}$. The CGNs were well dispersed, and the average diameter of the CGNs was about $24 \mathrm{~nm}$. Moreover, the CGNs had a maximum UV absorption wavelength at $517 \mathrm{~nm}$ (Figure 3b). When it was combined with anti-AME mAb, the UV absorption wavelength had a red-shift. Here, the UV absorption wavelength of CGNs-mAb conjugates was $524 \mathrm{~nm}$. The results indicated that the CGNs were well prepared, and anti-AME mAb was also successfully conjugated with CGNs.
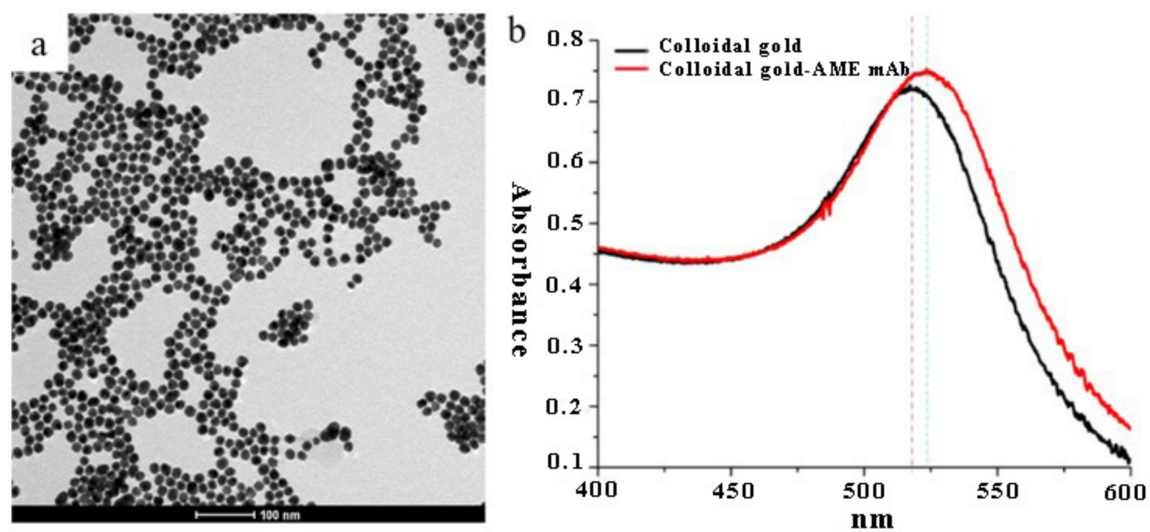

Figure 3. TEM image of colloidal gold nanoparticles (CGNs) (a) and UV spectrum of the CGNs-mAb conjugates (b). The black line and red line in $\mathbf{b}$ represent CGNs and CGNs-mAb conjugates, respectively. 


\subsection{Assembly and Competitive Detection Principle of Immunochromatographic Strip}

An immunochromatographic strip for the on-site detection of AME toxins was developed. Figure 4 shows the format and competitive detection principle. When AME toxins are present in a sample solution, they will be captured by the CGNs-mAb and formed CGNs-mAb-AME conjugates in conjugate pad firstly. The conjugates will be captured by the goat anti-mouse IgG in the C line, whereas they can not be captured by the AME- ovalbumin (OVA) in the T line. As such, for positive results the $\mathrm{T}$ line does not show the red color while the $\mathrm{C}$ line does show the red color. When the sample solution does not contain AME toxins, the CGNs-mAb conjugates will be captured by AME-OVA and goat anti-mouse IgG in the $\mathrm{T}$ line and the $\mathrm{C}$ line, respectively. As such, for negative results both the $\mathrm{T}$ line and the $\mathrm{C}$ line show the red color.

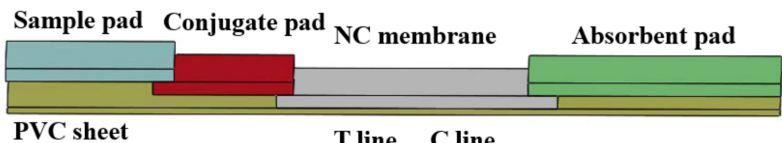

T line C line

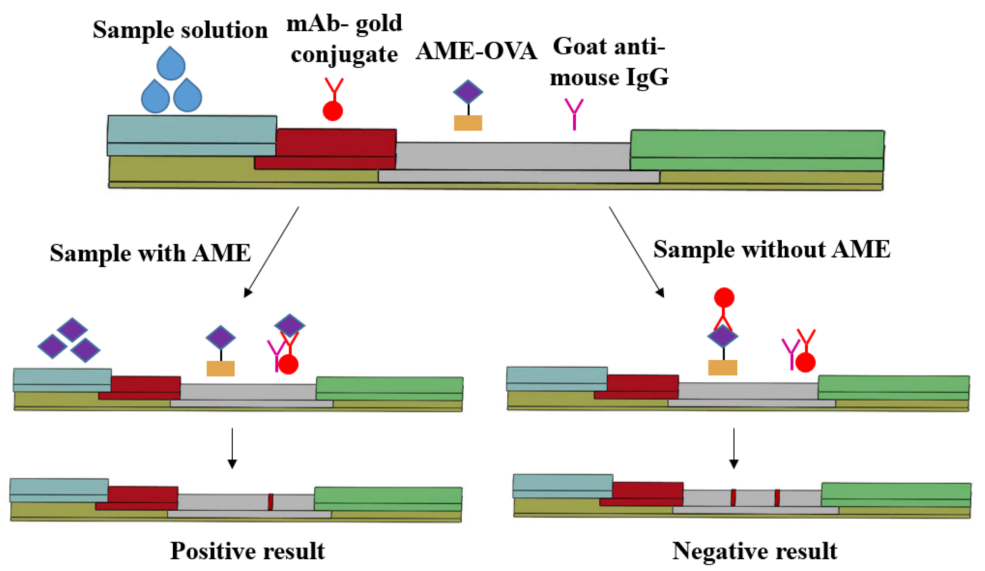

Figure 4. Schematic illustration of immunochromatographic strip. The $\mathrm{T}$ line (test line) and $\mathrm{C}$ line (control line) was coated by AME- ovalbumin (OVA) and goat anti-mouse IgG, respectively.

\subsection{Limit of Detection (LOD) of the Prepared Immunochromatographic Strip}

Several standard solutions of AME at the concentrations of 50,40,30, 20, 10, 5, 1, 0.1, and $0 \mathrm{ng} / \mathrm{mL}$ were prepared by diluting AME $(1 \mathrm{mg} / \mathrm{mL}$ in dimethylformamide (DMF)) with PBS. These AME standard solutions $(70 \mu \mathrm{L})$ were measured by the immunochromatographic strips. The results were judged by visualization within $10 \mathrm{~min}$. As shown in Figure 5, the intensity of red density on $\mathrm{T}$ lines reduced when the concentration of AME toxins increased. The color intensity of the colloidal gold immunochromatographic strip tests is inversely proportional to AME concentrations in the range $0.1-10 \mathrm{ng} / \mathrm{mL}$. The visual LOD of AME immunochromatographic strip is defined as the concentration of AME standard solution that causes the T line to be completely invisible. Therefore, the LOD of the strip test for AME was about $10 \mathrm{ng} / \mathrm{mL}$. When the AME concentration was above the LOD, there was not a red line on the $\mathrm{T}$ line, and there was only one red line on the $\mathrm{C}$ line. On the contrary, if there are two red lines on the nitrocellulose (NC) membrane, it shows that the concentration of AME in sample is below the LOD. 


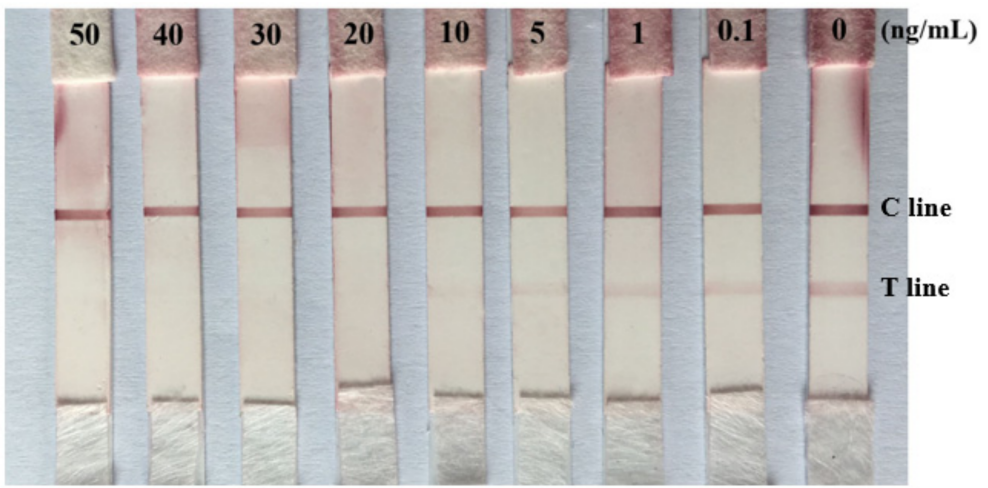

Figure 5. Limit of detection (LOD) of AME with colloidal gold immunochromatographic strip. A series of dilutions $(0-50 \mathrm{ng} / \mathrm{mL})$ of AME standard solutions were prepared by diluting AME in PBS. When the concentration of AME was higher than $10 \mathrm{ng} / \mathrm{mL}$, the red line at the $\mathrm{T}$ line disappeared.

\subsection{Cross Reactivity Test of the Prepared Immunochromatographic Strip}

$\mathrm{AOH}, \mathrm{ALT}$, and tenuazonic acid (TeA) have similar structures to AME. They were chosen to study the cross reactivity of the prepared immunochromatographic strips. The concentrations of 400 , 200, and $100 \mathrm{ng} / \mathrm{mL}$ of $\mathrm{AOH}, \mathrm{ALT}$, and TeA were used in the prepared immunochromatographic strips, respectively. As shown in Figure 6, when the concentrations of AOH, ALT, and TeA were at 100,200 , and $400 \mathrm{ng} / \mathrm{mL}$, the intensity of the red color at $\mathrm{T}$ lines was slightly weaker compared to that of $0 \mathrm{ng} / \mathrm{mL}$, but the loss of the intensity of red density was not significant. Hence, no significant cross-reactivity was observed with $\mathrm{AOH}, \mathrm{ALT}$, and TeA. All of the results indicated that the presence of these mycotoxins $(\mathrm{AOH}, \mathrm{ALT}$, and $\mathrm{TeA})$ in the test sample did not interfere with the detection of AME. As such, the prepared immunochromatographic strips have good specificity.
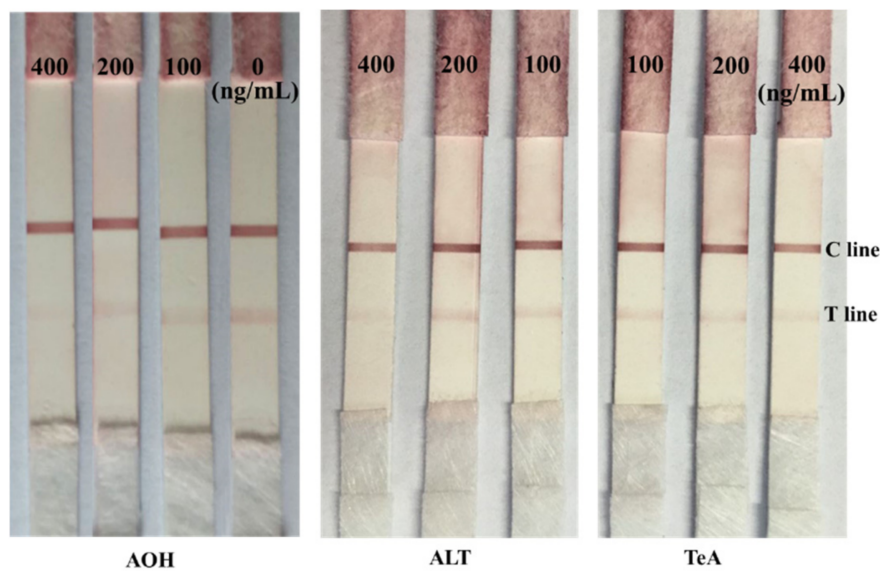

Figure 6. Cross reactivity of the immunochromatographic strip with alternariol $(\mathrm{AOH})$, altenuene (ALT), and tenuazonic acid (TeA).

\subsection{The Stability Performance of the Immunochromatographic Strip for the Detection of AME}

A batch of assembly completed immunochromatographic strips were prepared at the same time. Some of them (stored 0 days) were used for studying the detection limit (Figure 5). Other immunochromatographic strips were kept at room temperature for 3 months in a zip-lock plastic bag containing silica gel desiccant and were used for evaluating the stability performance. These strips were used for the detecting a series of different concentrations AME of $0,0.1,1,5,10$, 20, 30, $40 \mathrm{ng} / \mathrm{mL}$. The results of Figure 7 showed that the density of the color on $\mathrm{T}$ line and $\mathrm{C}$ line seem slightly weaker compared to those immunochromatographic strips which were stored 0 days, 
but the loss of the intensity of red density was not significant. The results showed that the colloidal gold immunochromatographic strip developed in this study has good stability, and it may be suitable as a commercial kit for rapid detection.

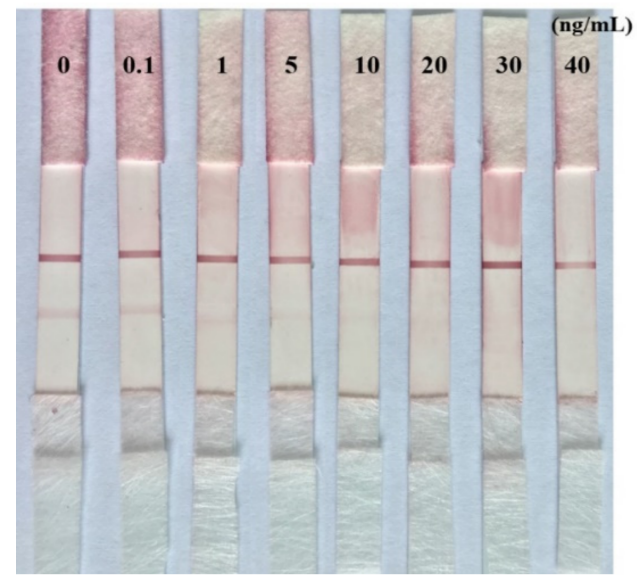

Figure 7. The AME test results of immunochromatographic strips after storage for 3 months at room temperature. The concentrations of AME were $0,0.1,1,5,10,20,30$, and $40 \mathrm{ng} / \mathrm{mL}$, respectively.

\subsection{Application of the Immunochromatographic Strip to Spiked Fruit Samples}

In order to apply the immunochromatographic strip to a real sample matrix, fruit samples of cherries and oranges spiked with AME standards were determined by the prepared colloidal gold immunochromatographic strip. The recoveries of AME in spiked cherry and orange fruits determined by competitive ELISA were $86.1 \%$ and $80.7 \%$, respectively. The AME concentrations of $0,1,5,10$, and $20 \mathrm{ng} / \mathrm{mL}$ in cherries were prepared by diluting the extracted samples using PBS buffer. Then the extracted cherry samples were detected by the immunochromatographic strip. Additionally, the spiked concentrations of AME in orange $(0,1$, and $10 \mathrm{ng} / \mathrm{mL})$ were also detected by the immunochromatographic strip. All of the experiments were repeated three times. The detection results are shown in Figure 8. The density of the red color at $\mathrm{T}$ line and $\mathrm{C}$ line was similar to the result of Figure 5. When the concentration of AME toxins increased, the intensity of the red color on $\mathrm{T}$ lines reduced. The detection limit of the strip for AME was also about $10 \mathrm{ng} / \mathrm{mL}$. All of the results indicated that the real sample matrix has very little impact on the detection result of the strip, and the immunochromatographic strips were reliable for AME detection in fruits.

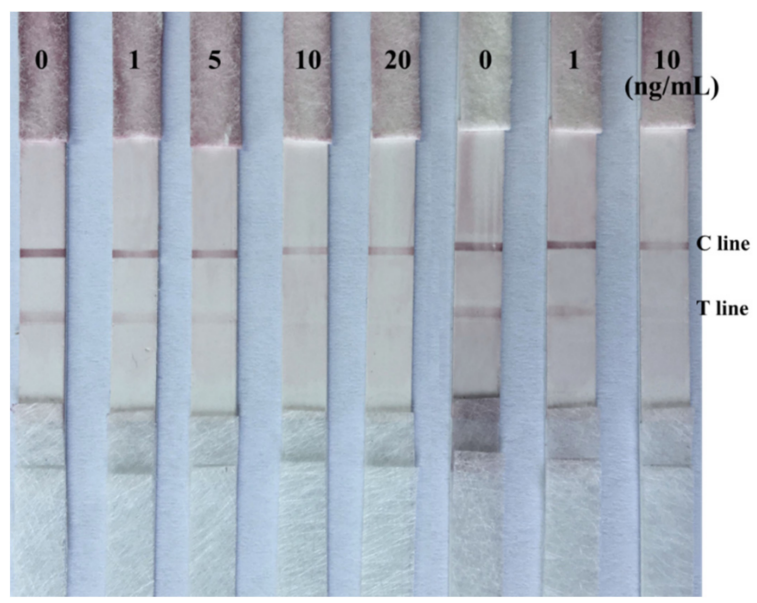

Figure 8. Immunochromatographic strip test of AME in spiked cherry and orange samples. The spiked concentrations of AME in cherry were $0,1,5,10$, and $20 \mathrm{ng} / \mathrm{mL}$, and in orange were 0,1 , and $10 \mathrm{ng} / \mathrm{mL}$. 


\section{Discussion}

Alternariol monomethyl ether (AME) toxin is one of the most commonly found Alternaria mycotoxins in fruits and their processed products. AME could cause serious diseases in humans and animals because of its mutagenicity, teratogenicity, and carcinogenicity. Although the statutory or guideline limits have not been set for AME toxin in food and agricultural products by the regulatory authorities, recently the European Standing Committee suggested that EU member states should collect the occurrence data of Alternaria mycotoxins containing AME toxin in food. In addition, the European Food Safety Authority (EFSA) has published its scientific opinion about the health risk of AME toxin in food and feed [2]. So, the problem of food safety about AME toxin has caused wide public concern over the recent years.

Similar to most mycotoxins, AME is also a low molecular weight nonimmunogenic toxin, so it is necessary to couple AME with carrier proteins for antibody production. Structurally, AME does not have active groups that can be conjugated with the carrier protein bovine serum albumin (BSA). Thus, in this study, a carboxylic group from methyl 4-bromobutanoate was linked to the carbonyl group of AME toxin through derivation, allowing AME toxin to covalently bind with the amino group of BSA carrier protein. NMR and HPLC-MS results showed that the AME linked carboxylic acid was successfully obtained. The conjugation of AME linked carboxylic acid and BSA was prepared through the amide bonds using 1-ethyl-3-(3-dimethylaminopropyl) carbodiimide hydrochloride (EDC) and the dehydrating agent N-hydroxysuccinimide (NHS). AME-BSA was used for immunization, the anti-AME $m A b$ was obtained and displayed a higher affinity for AME, the antibody titer $(>1: 90,000)$ was obtained, and the $\mathrm{IC}_{50}$ values of AME was $0.227 \mathrm{ng} / \mathrm{mL}$. The selected anti-AME monoclonal antibody showed lower cross-reactivity (2.1\%) with the AME analogues AOH. So far, there are still no relevant reports about the preparation and use of the AME monoclonal antibody.

A competitive colloidal gold immunochromatographic strip for the detection of AME in fruit samples has been developed using the selected anti-AME mAb. The CGNs were round in shape and well dispersed. The smaller particle size of CGNs means that they have a larger specific surface, could combine a larger amount of antibodies, and have good stability, but had a lighter red color on $\mathrm{T}$ line, and vice versa. The average diameter of CGNs was about $24 \mathrm{~nm}$, which was widely used in previous literature [22,26]. The naked CGNs had a UV absorption wavelength at $517 \mathrm{~nm}$. When it was covered with anti-AME $\mathrm{mAb}$ by strong electrostatic interaction, the UV absorption wavelength experienced a red-shift [27]. Here, the UV absorption wavelength of colloidal gold-mAb conjugates was $524 \mathrm{~nm}$. The intensity of red density of the test line ( $\mathrm{T}$ line) was inversely proportional to AME concentration in the range $0.1-10 \mathrm{ng} / \mathrm{mL}$. The visual limit of detection (LOD) of AME was found to be about $10 \mathrm{ng} / \mathrm{mL}$. Recently, the detection of some other mycotoxins also used the same typical method, and similar results were also obtained. For example, the detection limits of 50,5, 40, and $20 \mathrm{ng} / \mathrm{mL}$ were obtained with the naked eyes for deoxynivalenol [18], ochratoxin A [15], T-2 [25], and zearalenone [22,26], respectively. The prepared immunochromatographic strips showed no significant cross-reactivity with $\mathrm{AOH}, \mathrm{ALT}$, and TeA which have a structure similar to AME. The results indicated that the presence of these mycotoxins in the test sample did not interfere with the detection of AME. In addition, the strips could be used for 3 months without significant loss of activity. All of the results showed that the prepared immunochromatographic strips have good specificity and stability.

Finally, the prepared colloidal gold immunochromatographic strips were used for the detection of the cherry and orange samples spiked with AME standards. The results showed that the real sample matrix has very little impact on the detection result of the strips. All of the results indicated that the proposed competitive colloidal gold immunochromatographic strips developed in this work are suited for real-time, rapid, or portable semi-quantitative detection of AME toxin in fruits. Moreover, it may be suitable as a commercial kit for AME detection. Furthermore, the antibodies of other main Alternaria mycotoxins (such as $\mathrm{AOH}, \mathrm{TeA}$, etc.) were also produced. Then the immunochromatographic strips were prepared using the antibodies for the simultaneous, rapid, portable, and visual detection of multiple Alternaria mycotoxins. 


\section{Materials and Methods}

\subsection{Materials}

Alternariol $(\mathrm{AOH})$, alternariol monomethyl ether (AME), altenuene (ALT), tenuazonic acid (TeA), N, N-dicyclohexylcarbodiimide (DCC), N-hydroxysuccinimide (NHS), and gold chloride $\left(\mathrm{HAuCl}_{4} \cdot 3 \mathrm{H}_{2} \mathrm{O}\right)$ were purchased from Sigma-Aldrich (Shanghai, China). Bovine serum albumin (BSA), human serum albumin (HSA), methyl 4-bromobutanoate, trisodium citrate dihydrate, and Tween-20 were purchased from Amresco (CochranSolon, OH, USA). PEG20000 was purchased from Alfa Aesar Chemical Co., Ltd. (Shanghai, China). Acetonitrile (HPLC grade) were purchased from Thermo Fisher Scientific (Waltham, NJ, USA). Incomplete Freund's adjuvant, complete Freund's adjuvant, 96-well microplates, goat anti-mouse IgG, and developing solution was offered by Beijing Kwinbon Biotechnology Co., Ltd. (Beijing, China). Polyvinyl chloride (PVC) sheet, NC membrane (Millipore 135), absorbent pad, conjugate pad, and sample pad were obtained from Shanghai Kinbio Tech. Co., Ltd. (Shanghai, China). Analytical grade sodium chloride $(\mathrm{NaCl})$, dimethylformamide (DMF), methyl 4-bromobutanoate, potassium carbonate $\left(\mathrm{K}_{2} \mathrm{CO}_{3}\right)$, ethanol, petroleum ether, tetrahydrofuran (THF), lithium hydroxide $(\mathrm{LiOH})$, ethyl acetate (EtOAc), and other chemicals and solvents were ordered from Beijing Chemical Reagent Co. (Beijing, China). Water was deionized and purified with a Milli-Q system (Millipore, Bedford, MA, USA).

\subsection{Carboxyl Derivative Modification of AME}

AME derivative with carboxyl group was synthesized as follows. Methyl 4-bromobutanoate (145 mg, $0.80 \mathrm{mmol})$ and $\mathrm{K}_{2} \mathrm{CO}_{3}(302 \mathrm{mg}, 2.19 \mathrm{mmol})$ were added to a solution of AME (200 mg, $0.73 \mathrm{mmol})$ in DMF $(10 \mathrm{~mL})$. The resulting solution was stirred at $50{ }^{\circ} \mathrm{C}$ for $2 \mathrm{~h}$. Then the mixture was cooled, diluted with $\mathrm{H}_{2} \mathrm{O}(20 \mathrm{~mL})$, and extracted with ethanol $(3 \times 20 \mathrm{~mL})$. The organic phase was combined, dried, and concentrated. The residue was purified by column chromatography on silica gel (petroleum ether:ethanol = 2:1) to give AME linked methyl ester (compound 1) as a light yellow solid (205 $\mathrm{mg})$.

$\mathrm{H}_{2} \mathrm{O}(1 \mathrm{~mL})$ was added to a solution of compound $1(150 \mathrm{mg}, 0.40 \mathrm{mmol})$ in $\mathrm{CH}_{3} \mathrm{OH}(5 \mathrm{~mL})$, THF (5 mL), LiOH (18 mg, $1.20 \mathrm{mmol})$. The resulting solution was stirred at room temperature for $5 \mathrm{~h}$. The solvent was concentrated and the residue was diluted with $\mathrm{H}_{2} \mathrm{O}(5 \mathrm{~mL})$, adjusted to $\mathrm{pH}=4$, and then extracted with ethyl acetate (EtOAc) $(3 \times 10 \mathrm{~mL})$. The organic phase was combined, dried and concentrated, and recrystallized by EtOAc to give AME linked carboxylic acid (compound 2) as a white solid (40 mg).

\subsection{Preparation of $A M E-B S A$ and $A M E-O V A$}

AME-BSA was prepared according to the following steps. DCC (13.7 $\mathrm{mg}$ ) was added was added to a solution of AME linked carboxylic acid $(15.8 \mathrm{mg})$ in DMF $(1.5 \mathrm{~mL})$. The mixture was stirred for $30 \mathrm{~min}$, and then added with NHS $(7.6 \mathrm{mg})$. The solution was stirred at room temperature under dark conditions for $3.5 \mathrm{~h}$. The precipitation was removed by centrifugation. The supernatant was added dropwise into the bovine serum albumin (BSA) solution (0.1 M), which was stirred at $4{ }^{\circ} \mathrm{C}$ under dark conditions for $2 \mathrm{~h}$. In addition, to prepare AME-OVA, AME linked carboxylic acid (9.2 mg) and EDC (7.4 mg) were added to DMF (2 mL), and stirred for $20 \mathrm{~min}$. The resulting solution was added dropwise into the ovalbumin (OVA) solution $(10 \mathrm{mg} / \mathrm{mL})$, which was stirred at $4{ }^{\circ} \mathrm{C}$ under dark conditions for $24 \mathrm{~h}$. Finally, the solution of AME-BSA and AME-OVA were dialyzed using PBS buffer for $72 \mathrm{~h}$, with three changes of PBS every $24 \mathrm{~h}$.

\subsection{Preparation of Anti-AME $m A b$}

The Balb/c mouse was immunized with $200 \mu \mathrm{g}$ of AME-BSA in PBS buffer, which was mixed with comparable amount of complete Freund's adjuvant. From the second immunity to the fourth immunity, the complete Freund's adjuvant was replaced by incomplete Freund's adjuvant. The interval time of 
each immunity was 15 days. When the titer of serum was relatively high, the booster immunization was implemented using $200 \mu \mathrm{g}$ AME-BSA. After 15 days, spleen cells of the immunized mice and SP2/0 cells were fused, and the positive cell clones were screened using limited dilution method. The ascites monoclonal antibodies (mAbs) were prepared using the conventional technique, and purified by saturated ammonium sulfate.

\subsection{Competitive ELISA}

A 96-well microplate was coated with AME-OVA for $2 \mathrm{~h}$ at $37^{\circ} \mathrm{C}$, and then was placed overnight at $4{ }^{\circ} \mathrm{C}$. AME, diluted in PBS at $0,0.01,0.1,0.3,0.9,2.7$, and $8.1 \mathrm{ng} / \mathrm{mL}$, was mixed with equal volume anti-AME mAb (90,000-fold diluted in PBS) for $30 \mathrm{~min}$ at $37^{\circ} \mathrm{C}$, respectively. The resulting solution was added to the 96 -well microplate $(100 \mu \mathrm{L} /$ well $)$, and incubated for $30 \mathrm{~min}$ at $37^{\circ} \mathrm{C}$. Following a washing step, goat anti-mouse IgG was added $(50 \mu \mathrm{L} /$ well). Developing solution $(100 \mu \mathrm{L} /$ well $)$ was added and incubated for $15 \mathrm{~min}$ at $37^{\circ} \mathrm{C}$, and then was stopped with $2 \mathrm{M} \mathrm{HCl} \mathrm{(50 \mu L/well).}$ The optical densities (ODs) were measured at $450 \mathrm{~nm}$ using a microplate reader.

\subsection{Preparation of Colloidal Gold Nanoparticles (CGNs) and CGNs-mAb Conjugates}

Colloidal gold nanoparticles (CGNs) and the colloidal gold-mAb conjugates were prepared according to the previous approach with minor modification [28]. Monoclonal antibodies concentration and $\mathrm{pH}$ for conjugation of $\mathrm{mAbs}$ with CGNs were optimized (see Supplementary Material). Briefly, $0.01 \% \mathrm{HAuCl}_{4}$ solution $(100 \mathrm{~mL})$ was boiled, and $1 \%$ trisodium citrate solution $(1.6 \mathrm{~mL})$ was subsequently and rapidly added into the boiling solution. Then the solution was boiled for $10 \mathrm{~min}$ and cooled down to room temperature. The conjugation conditions between CGNs and anti-AME $\mathrm{mAb}$, including the $\mathrm{mAb}$ concentration and the $\mathrm{pH}$, were optimized before conjugation. The results showed that the optimal mAbs concentration was $7.2 \mu \mathrm{g} / \mathrm{mL}$ and the optimal $\mathrm{pH}$ value of colloidal gold was 8.0. The conjugation of colloidal gold with anti-AME $\mathrm{mAb}$ was conducted according to the following method. Briefly, $5 \mathrm{~mL}$ of CGNs was mixed with $40 \mu \mathrm{g}$ of mAbs, incubated for $2 \mathrm{~h}$ at room temperature, and then was blocked by BSA solution. After incubation, colloidal gold-mAb conjugates were purified and concentrated by centrifugation. Finally, the colloidal gold-mAb conjugates were resuspended in $0.5 \mathrm{~mL}$ of Tris- $\mathrm{HCl}$ buffer $(10 \mathrm{mM})$ containing $5 \%$ sucrose, $1 \%$ BSA, $0.1 \%$ Tween-20, and $0.1 \%$ PEG 20000.

\subsection{Preparation of Colloidal Gold Immunochromatographic Strip}

The colloidal gold immunochromatographic strips were prepared as previously described [13,19]. The immunochromatographic strips were assembled by the sample pad, conjugate pad, nitrocellulose (NC) membrane, absorption pad, and polyvinyl chloride (PVC) soleplate. A total of $1 \mu \mathrm{L}$ per $1 \mathrm{~cm}$ of AME-OVA conjugates $(2 \mathrm{mg} / \mathrm{mL})$ and goat anti-mouse $\mathrm{IgG}$ antibody $(1 \mathrm{mg} / \mathrm{mL})$ was sprayed onto NC membrane as the test line ( $\mathrm{T}$ line) and control line ( $\mathrm{C}$ line), respectively, and then dried at $37^{\circ} \mathrm{C}$ for $2 \mathrm{~h}$. The distance between the $\mathrm{T}$ line and the $\mathrm{C}$ line was $5 \mathrm{~mm}$. The whole assembled sheet was cut into strips $(5 \mathrm{~mm} \times 60 \mathrm{~mm})$. The strips were stored under dry conditions for further use at room temperature.

\subsection{Samples and Preparation}

The sample was extracted according to Wang et al. [29]. Orange and cherry fruits were purchased from local markets. One kilogram of orange and cherry were cut into small pieces, and then comminuted to a mash by a homogenizer. The homogenized cherry $(5 \mathrm{~g})$ and orange $(5 \mathrm{~g})$ were placed into $50 \mathrm{~mL}$ centrifugation tubes, and added with water to $5 \mathrm{~mL}$. Subsequently, $2 \mu \mathrm{L}$ of $\mathrm{AME}$ standard sample $(1 \mathrm{mg} / \mathrm{mL})$ and $20 \mathrm{~mL}$ of the acetonitrile containing citric acid $(100 \mathrm{mM})$ were added. The centrifugation tubes were shaken for $30 \mathrm{~min}$ at $150 \mathrm{rpm}$. Then $\mathrm{NaCl}(2 \mathrm{~g})$ was added and centrifuged at $10000 \mathrm{rpm}$ for $5 \mathrm{~min}$. The upper acetonitrile layer was purified by the SPE cartridge. The extract of $4 \mathrm{~mL}$ was dried under nitrogen, and reconstituted with $0.1 \mathrm{~mL}$ acetonitrile. Finally, 
the reconstituted solution was diluted using $0.4 \mathrm{~mL}$ PBS buffer. The recoveries of AME in cherry and orange were detected by competitive ELISA, respectively.

Supplementary Materials: The following are available online at www.mdpi.com/2072-6651/9/5/152/s1, Figure S1: Determination of the optimal monoclonal antibodies concentration by visual observation, Table S1: The optimal monoclonal antibodies concentration by visual observation, Figure S2: The optimal $\mathrm{pH}$ value determination of colloidal gold by visual observation, Table S2: The optimal $\mathrm{pH}$ value determination of colloidal gold by visual inspection.

Acknowledgments: This work was supported by the National Key Research and Development Program of China (2016YFD0400902), China Postdoctoral Science Foundation (2015M581020), the Project of Beijing Excellent Talents (2016000020060G127), the Special Projects of Construction of Science and Technology Innovation Ability of Beijing Academy of Agriculture and Forestry Sciences (KJCX20170420, KJCX20150408), and the Beijing Postdoctoral Research Foundation.

Author Contributions: Yan Man and Ligang Pan conceived and designed the experiments; Yan Man performed the experiments; Gang Liang, An Li and Hailong Fu analyzed the data; Yan Man and Fuchao Jia wrote the paper; Meng Wang contributed materials.

Conflicts of Interest: The authors declare no conflicts of interest.

\section{References}

1. Alexander, J.; Benford, D.; Boobis, A.; Ceccatelli, S.; Cottrill, B.; Cravedi, J.; Di Domenico, A.; Doerge, D.; Dogliotti, E.; Edler, L. Scientific opinion on the risks for animal and public health related to the presence of Alternaria toxins in feed and food. EFSA J. 2011, 9, 2407-2504.

2. Man, Y.; Liang, G.; Li, A.; Pan, L. Analytical methods for the determination of Alternaria mycotoxins. Chromatographia 2016, 80, 1-14. [CrossRef]

3. Olsen, M.; Visconti, A. Metabolism of alternariol monomethyl ether by porcine liver and intestinal mucosa in vitro. Toxicol. In Vitro 1988, 2, 27-29. [CrossRef]

4. Liu, G.T.; Qian, Y.Z.; Zhang, P.; Dong, W.H.; Qi, Y.M.; Guo, H.T. Etiological role of Alternaria alternata in human esophageal cancer. Chin. Med. J. 1992, 105, 394-400. [PubMed]

5. Pfeiffer, E.; Eschbach, S.; Metzler, M. Alternaria toxins: DNA strand-breaking activity in mammalian cellsin vitro. Mycotoxin Res. 2007, 23, 152-157. [CrossRef] [PubMed]

6. Marko, D. Mechanisms of the genotoxic effect of Alternaria toxins, Gesellschaft fur Mykotoxin Forschung. In Proceedings of the 29th Mycotoxin Workshop, Stuttgart-Fellbach, Germany, 14-16 May 2007.

7. Ostry, V. Alternaria mycotoxins: An overview of chemical characterization, producers, toxicity, analysis and occurrence in foodstuffs. World Mycotoxin J. 2008, 1, 175-188. [CrossRef]

8. Köppen, R.; Koch, M.; Siegel, D.; Merkel, S.; Maul, R.; Nehls, I. Determination of mycotoxins in foods: Current state of analytical methods and limitations. Appl. Microbiol. Biotechnol. 2010, 86, 1595-1612. [PubMed]

9. Scott, P.; Weber, D.; Kanhere, S. Gas chromatography-mass spectrometry of Alternaria mycotoxins. J. Chromatogr. A 1997, 765, 255-263. [CrossRef]

10. Hickert, S.; Bergmann, M.; Ersen, S.; Cramer, B.; Humpf, H.-U. Survey of Alternaria toxin contamination in food from the German market, using a rapid HPLC-MS/MS approach. Mycotoxin Res. 2015, 32, 1-12. [CrossRef] [PubMed]

11. Walravens, J.; Mikula, H.; Rychlik, M.; Asam, S.; Devos, T.; Njumbe Ediage, E.; Diana Di Mavungu, J.; Jacxsens, L.; Van Landschoot, A.; Vanhaecke, L.; et al. Validated UPLC-MS/MS methods to quantitate free and conjugated Alternaria toxins in commercially available tomato products and fruit and vegetable juices in Belgium. J. Agric. Food Chem. 2016, 64, 5101-5109. [CrossRef] [PubMed]

12. Walravens, J.; Mikula, H.; Rychlik, M.; Asam, S.; Ediage, E.N.; Di Mavungu, J.D.; Van Landschoot, A.; Vanhaecke, L.; De Saeger, S. Development and validation of an ultra-high-performance liquid chromatography tandem mass spectrometric method for the simultaneous determination of free and conjugated Alternaria toxins in cereal-based foodstuffs. J. Chromatogr. A 2014, 1372, 91-101. [CrossRef] [PubMed]

13. Kong, D.; Liu, L.; Song, S.; Suryoprabowo, S.; Li, A.; Kuang, H.; Wang, L.; Xu, C. A gold nanoparticle-based semi-quantitative and quantitative ultrasensitive paper sensor for the detection of twenty mycotoxins. Nanoscale 2016, 8, 5245-5253. [CrossRef] [PubMed] 
14. Cho, Y.J.; Lee, D.H.; Kim, D.O.; Min, W.K.; Bong, K.T.; Lee, G.G.; Seo, J.H. Production of a monoclonal antibody against ochratoxin $\mathrm{A}$ and its application to immunochromatographic assay. J. Agric. Food Chem. 2005, 53, 8447-8451. [CrossRef] [PubMed]

15. Liu, B.H.; Tsao, Z.J.; Wang, J.J.; Yu, F.Y. Development of a monoclonal antibody against ochratoxin A and its application in enzyme-linked immunosorbent assay and gold nanoparticle immunochromatographic strip. Anal. Chem. 2008, 80, 7029-7035. [CrossRef] [PubMed]

16. Majdinasab, M.; Zeinoddin, M.S.; Zad, S.S.; Li, P.; Zhang, Q.; Li, X.; Tang, X. Ultrasensitive and quantitative gold nanoparticle-based immunochromatographic assay for detection of ochratoxin A in agro-products. J. chromatogr. B 2015, 974, 147-154. [CrossRef] [PubMed]

17. Huang, Z.-B.; Xu, Y.; Li, L.S.; Li, Y.P.; Zhang, H.; He, Q.H. Development of an immunochromatographic strip test for the rapid simultaneous detection of deoxynivalenol and zearalenone in wheat and maize. Food Control 2012, 28, 7-12. [CrossRef]

18. Xu, Y.; Huang, Z.-B.; He, Q.-H.; Deng, S.Z.; Li, L.S.; Li, Y.P. Development of an immunochromatographic strip test for the rapid detection of deoxynivalenol in wheat and maize. Food Chem. 2010, 119, 834-839. [CrossRef]

19. Liu, J.-W.; Lu, C.-C.; Liu, B.-H.; Yu, F.Y. Development of novel monoclonal antibodies-based ultrasensitive enzyme-linked immunosorbent assay and rapid immunochromatographic strip for aflatoxin $\mathrm{B}_{1}$ detection. Food Control 2016, 59, 700-707. [CrossRef]

20. Wang, J.J.; Liu, B.H.; Hsu, Y.T.; Yu, F.Y. Sensitive competitive direct enzyme-linked immunosorbent assay and gold nanoparticle immunochromatographic strip for detecting aflatoxin $\mathrm{M}_{1}$ in milk. Food Control 2011, 22, 964-969. [CrossRef]

21. Li, Y.S.; Zhou, Y.; Lu, S.Y.; Guo, D.J.; Ren, H.L.; Meng, X.M.; Zhi, B.H.; Lin, C.; Wang, Z.; Li, X.B.; et al. Development of a one-step test strip for rapid screening of fumonisins B1, B2 and B3 in maize. Food Control 2012, 24, 72-77. [CrossRef]

22. Sun, Y.; Hu, X.; Zhang, Y.; Yang, J.; Wang, F.; Wang, Y.; Deng, R.; Zhang, G. Development of an immunochromatographic strip test for the rapid detection of zearalenone in corn. J. Agric. Food Chem. 2014, 62, 11116-11121. [CrossRef] [PubMed]

23. He, K.; Zhang, X.; Zhao, R.; Wang, L.; Feng, T.; Wei, D. An enzyme-linked immunosorbent assay and a gold-nanoparticle based immunochromatographic test for amatoxins using recombinant antibody. Microchimi. Acta 2016, 183, 2211-2219. [CrossRef]

24. Molinelli, A.; Grossalber, K.; Führer, M.; Baumgartner, S.; Sulyok, M.; Krska, R. Development of qualitative and semiquantitative immunoassay-based rapid strip tests for the detection of T-2 toxin in wheat and oat. J. Agric. Food Chem. 2008, 56, 2589-2594. [CrossRef] [PubMed]

25. Zhang, X.; Wu, C.; Wen, K.; Jiang, H.; Shen, J.; Zhang, S.; Wang, Z. Comparison of Fluorescent Microspheres and Colloidal Gold as Labels in Lateral Flow Immunochromatographic Assays for the Detection of T-2 Toxin. Molecules 2016, 21, 27. [CrossRef] [PubMed]

26. Sun, Y.; Xing, G.; Yang, J.; Wang, F.; Deng, R.; Zhang, G.; Hu, X.; Zhang, Y. Development of an immunochromatographic test strip for simultaneous qualitative and quantitative detection of ochratoxin $\mathrm{A}$ and zearalenone in cereal. J. Agric. Food Chem. 2016, 96, 3673-3678. [CrossRef] [PubMed]

27. Tripathi, V.; Nara, S.; Singh, K.; Singh, H.; Shrivastav, T.G. A competitive immunochromatographic strip assay for 17- $\alpha$-hydroxy progesterone using colloidal gold nanoparticles. Clin. Chim. Acta 2012, 413, 262-268. [CrossRef] [PubMed]

28. Man, Y.; Lv, X.; Iqbal, J.; Peng, G.; Song, D.; Zhang, C.; Deng, Y. Microchip based and immunochromatographic strip assays for the visual detection of interleukin- 6 and of tumor necrosis factor $\alpha$ using gold nanoparticles as labels. Microchim. Acta 2015, 182, 597-604. [CrossRef]

29. Wang, M.; Jiang, N.; Xian, H.; Wei, D.; Shi, L.; Feng, X. A single-step solid phase extraction for the simultaneous determination of 8 mycotoxins in fruits by ultra-high performance liquid chromatography tandem mass spectrometry. J. Chromatogr. A 2016, 1429, 22-29. [CrossRef] [PubMed]

(C) 2017 by the authors. Licensee MDPI, Basel, Switzerland. This article is an open access article distributed under the terms and conditions of the Creative Commons Attribution (CC BY) license (http:/ / creativecommons.org/licenses/by/4.0/). 